Review Article

\title{
Clinical implications of the hyperdynamic syndrome in cirrhosis
}

\author{
Anna Licata *, Alessandra Mazzola, Daniela Ingrassia, Vincenza Calvaruso, Calogero Cammà, Antonio Craxì \\ Sezione di Gastroenterologia E Epatologia, Dipartimento Biomedico di Medicina Interna e Specialistica, DIBIMIS, Università di Palermo, Palermo, Italy
}

\section{A R T I C L E I N F O}

\section{Article history:}

Received 7 May 2014

Received in revised form 2 September 2014

Accepted 4 September 2014

Available online $\mathrm{xxxx}$

\section{Keywords:}

Cirrhosis

Hyperdynamic syndrome

Ascites

HRS

HPS

$\mathrm{CC}$

\begin{abstract}
A B S T R A C T
The hyperdynamic syndrome is a late consequence of portal hypertension in cirrhosis. The principal hemodynamic manifestations of the hyperdynamic syndrome are high cardiac output, and increased heart rate and total blood volume, accompanied by reduced total systemic vascular resistance. Pathophysiology involves a complex of humoral and neural mechanisms that can determine hemodynamic changes, and lead to hyperdynamic circulation.

In this review we focus our attention on the manifestations of the hyperdynamic syndrome. Some of these are well described and directly related to portal hypertension (varices, ascites, hepatic encephalopathy, and hepatorenal syndrome), while others, such as hepatopulmonary syndrome, portopulmonary hypertension, and cirrhotic cardiomyopathy, are less known as clinical manifestations related to cirrhosis and, therefore, merit further investigation.
\end{abstract}

@ 2014 European Federation of Internal Medicine. Published by Elsevier B.V. All rights reserved.

\section{Introduction}

Patients with advanced chronic liver disease show varying degrees of portal hypertension ( $\mathrm{PH})$ and splanchnic vasodilatation, which are often associated with a hyperdynamic circulatory state. The hyperdynamic syndrome (HS) is a consequence of cirrhosis of varying etiologies $[1,2]$. This syndrome has been defined by high cardiac output, increased heart rate and total blood volume, reduced total systemic vascular resistance, and low, normal or decreased arterial pressure [1-3]. In this review, we will attempt to describe and explain the pathophysiological and clinical manifestations related to HS.

\subsection{Hemodynamic changes contributing to hyperdynamic syndrome}

Among all hemodymanic alterations typical of advanced phases of cirrhosis, vasodilatation is the first of vascular changes that finally lead to multi-organ involvement. However, the mechanisms of vasodilation are still not entirely understood [2].

Abbreviations: HS, Hyperdynamic syndrome; PH, Portal hypertension; HPVG, Hepatic venous pressure gradient; HRS, Hepato-renal syndrome; HE, Hepatic encephalopathy; HPS, Hepatopulmonary syndrome; POPH, Portopulmonary hypertension; HH, Hepatic hydrothorax; CC, Cirrhotic cardiomyopathy; NO, Nitric oxide; CO, Carbon monoxide; SBP, Spontaneous bacterial peritonitis; TIPS, Transjugular intrahepatic portosystemic shunt; MELD, Model for End-Stage Liver Disease; PaO2, Partial pressure of oxygen; MPAP, Mean pulmonary artery pressure; BNP, Brain natriuretic peptide.

* Corresponding author at: Sezione di Gastroenterologia, DIBIMIS, University of Palermo, Piazza delle Cliniche 2, 90127, Palermo, Italy. Tel.: + 3909165522 80; fax: + 390916552156 .
Development of PH due to architectural changes typical of cirrhosis plays a fundamental role in the genesis of HS. In fact, PH consists of an increase in portal pressure gradient (HVPG), defined by the difference between the portal vein and the inferior vena cava pressures [4]. It is caused by an increased resistance to portal outflow and inflow, with an abnormal distribution of the blood volume, which increases mostly in the splanchnic district. This alteration of blood volume distribution with underfilling of arterial circulation triggers baroreceptor activation to release vasoconstrictor factors to restore integrity of the circulation [5]. Usually, the HVPG ranges from 1 to $5 \mathrm{mmHg}$, becoming clinically significant when it reaches $10 \mathrm{mmHg}$ [6]. In clinical practice, an increase in HPVG values of at least $12 \mathrm{mmHg}$ is usually associated with the presence of esophageal varices $[2,6]$. Progressing through the stages of cirrhosis, there is a wide development of a network of collateral vessels, which bypassing the liver, creates communication between the portal vein and the systemic circulation. The main collateral network is the gastro-epiploic system, responsible for the formation of gastroesophageal varices, which together with the reduction in circulating platelets and hypersplenism are the clinical hallmark of $\mathrm{PH}$ [5-7].

Splanchnic circulation is responsible for the reduction of vascular resistance in the portal hypertensive state. The increase in splanchnic blood flow is related to: 1.) an increase in vasodilatator factors (nitric oxide (NO), prostacyclines, carbon monoxide (CO), endocannabinoides); 2.) reduced response to vasoconstrictor factors; and 3.) mesenteric neoangiogenesis [8-11]. The increase in NO, maintained in pre-sinusoidal areas, is due to endothelial nitric oxide synthase activation by pro-inflammatory cytokines released by bacterial translocation and shear stress. Moreover, the splanchnic vasodilatation is caused by reduced response to vasoconstrictor 
factors, which, instead, are increased in other organs, such as the kidney and brain. The reduced response to local vasoconstrictors is likely related to increased levels of vasodilatator factors (NO, CO), and functional alterations of smooth muscular and endothelial cells.

At early compensated stages of cirrhosis, hyperdynamic circulation is not clinically manifest, but becomes more evident during the evolution of the disease. Any modification in peripheral resistance is rapidly compensated by variations in cardiac output. Though the reduction in peripheral resistance is slow, compensatory mechanisms play a pivotal role in maintaining and further worsening the hyperdynamic circulation (Fig. 1) [12-16]. Plasma volume expansion is relevant in these cirrhotic patients, even if distribution between the central and peripheral vascular areas is often not balanced [6,17]. The splanchnic vasodilation in cirrhosis precedes the increase in cardiac output and heart rate [18]. However, when the splanchnic vasodilatation becomes more pronounced, the hyperdynamic circulation may no longer be sufficient for correcting hypovolemia [12,17] (Fig. 2). Central arterial blood volume (heart, lungs, and central arterial tree blood volume) is more often decreased, while the non-central blood volume (splanchnic) is usually increased in cirrhotics.

\section{Clinical manifestations}

The first described clinical signs of the HS were arterial hypotension, wide pulse pressure, tachycardia, warm extremities and palmar erythema. Splanchnic vasodilatation is the first pathophysiological stage of clinical complications of cirrhosis, while $\mathrm{PH}$ and its sequelae are a cause of admission to the hospital, worsening of clinical conditions, and death. In fact, esophageal or gastric variceal bleeding, ascites with consequent spontaneous bacterial peritonitis (SBP), hepatic encephalopathy (HE), and hepato-renal syndrome (HRS) are closely related to PH.

However, the effects of hyperdynamic circulation also involve the heart (cirrhotic cardiomyopathy [CC]) and the lungs (hepatopulmonary syndrome [HPS], portopulmonary hypertension [POPH] and hepatic hydrothorax $[\mathrm{HH}]$ ). Clinical manifestations are listed in Table 1.

\subsection{Cutaneus and muscular manifestations}

Cutaneous and muscular circulations may be increased in patients with cirrhosis. Palmar erythema, spider nevi and potatory face were recognized early on as clinical signs of cutaneous hyperperfusion [19]. These manifestations are expressions of artero-venous fistulae, which result in increased perfusion of the capillary bed.

Contrasting data from the literature show that in cirrhotic patients muscular perfusion can be increased or normal [20,21]. Recent studies have reported that brachial and/or femoral artery blood flow investigated with Doppler techniques is normal, as is capillary skin blood flow studied by nuclear medicine techniques [22]. Thus, with the available data, it is not possible to determine the exact distribution of cardiac output among organs, tissues, and the capillary bed.

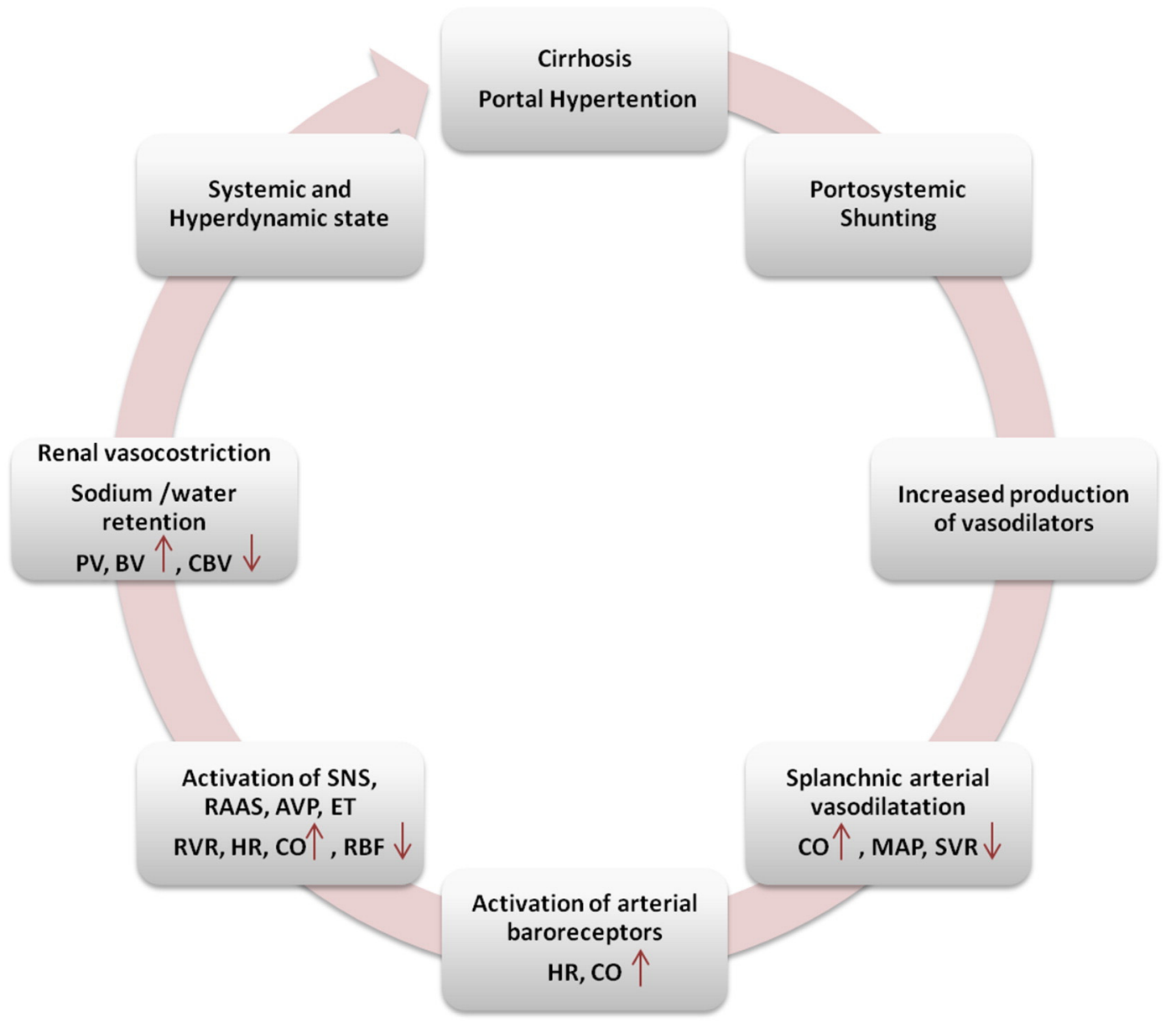

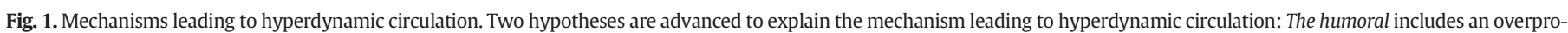

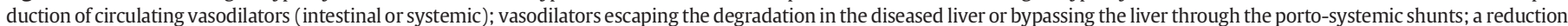

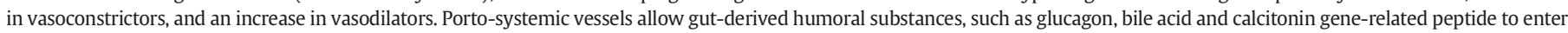

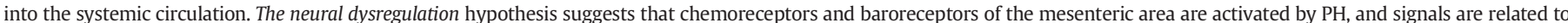

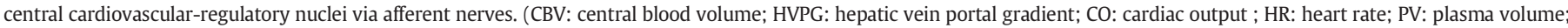

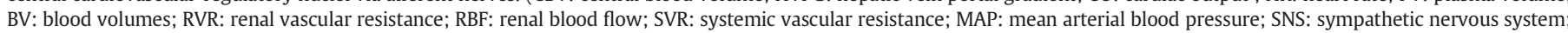
RAAS: renin-angiotensin-aldosterone system; AVP: arginine vasopressin; ET: endothelin). 


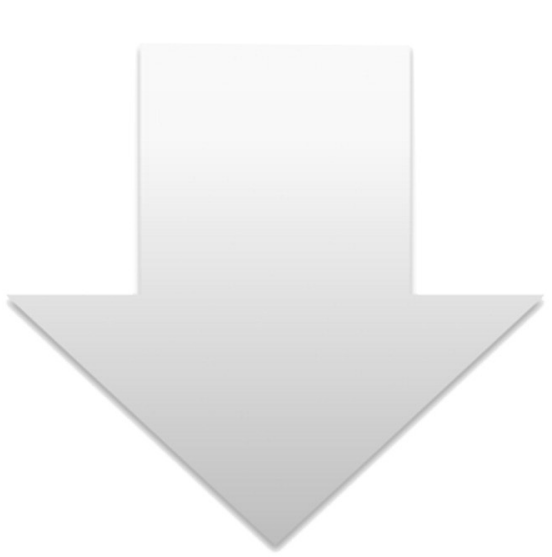

Vasodilators

- NO, TNF-a, PGI2, Hydrogen

sulphide,

- Adrenomedullin, ANP

Adenosine,

- Endocannabinoids,ET-3, Endotoxiin, Enkephaline, Glucagon

- BNP,Calcitonin gene-related peptide, $\mathrm{CO}$

\section{Vasocostrictors}

- AT II, Adrenaline and noradrenaline

- SNS, ET-1, Neuropeptide $Y$

- RAAS/ADH

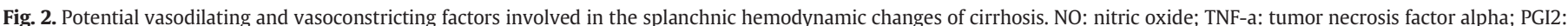

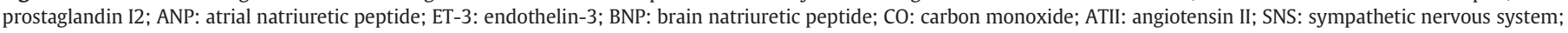
ET-1: endothelin-1; RAAS: renin-angiotensin-aldosterone system; ADH: vasopressin.

\subsection{Varices and bleeding}

The immediate clinical manifestations following the increase in portal pressure are esophageal varices and, eventually, their bleeding. Among compensated cirrhotic patients with elevated HVPG, gastrointestinal tract endoscopy reveals that $40 \%$ already have esophageal varices. Among those without varices, these will appear at a rate of $6 \%$ per year. Esophageal varices are present in approximately $30-40 \%$ patients with compensated cirrhosis at first observation, and in up to $60 \%$ of those with decompensation. Clinically, physical examination provides direct information on the presence of $\mathrm{PH}$. In fact, the presence of splenomegaly, spider nevi, and abdominal wall collateral circulation are indicative of $\mathrm{PH}$, though the sensitivity of physical signs in compensated cirrhotic patients is quite low. In a recent study, spider nevi were found to be independent predictors of esophageal varices [23].

Table 1

Clinical manifestations of the hyperdynamic syndrome.

\begin{tabular}{ll}
\hline Organs & Manifestations \\
\hline Muscle and skin & Palmar erythema; spider nevi (partially related) \\
Hepato-splanchnic & $\begin{array}{l}\text { Esophageal varices and bleeding; } \\
\text { ascites and spontaneous bacterial peritonitis }\end{array}$ \\
Kidney & Hepatorenal syndrome \\
Brain & Edema/Hepatic encephalopathy \\
Lungs & Hepatopulmonary syndrome, portopulmonary \\
& hypertension, hepatic hydrothorax \\
Heart & Cirrhotic cardiomyopathy \\
\hline
\end{tabular}

The gold-standard technique for assessing portal hypertension is the measurement of HVPG. Measurement of HVPG by catheterization of the right jugular vein (or the femoral or antecubital vein) is an invasive technique, which limits its use. Recently, spleen stiffness has been proposed as a new non-invasive parameter for predicting clinically significant portal hypertension and varices. Data on use of magnetic resonance, transient real-time elastography and ARFI appear more promising [23]. However, upper gastrointestinal tract endoscopy is still the gold standard for identifying esophageal and gastric varices, and is essential in the therapeutic management of variceal bleeding, through sclerotherapy and elastic band ligation [24].

Screening patients with endoscopy to prevent variceal rupture and bleeding is mandatory when a diagnosis of cirrhosis has been determined. The size of varices is semi-quantitatively graded as small, medium or large. Treatment recommendations in patients without varices includes endoscopy, to be repeated every 2-3 years because the incidence of esophageal varices is 5-10\%/year in this population [25]. In patients with small varices, an annual increase of $10-15 \%$ in size is observed. In these patients, endoscopy should be repeated every 1-2 years. Patients with small varices with red wale marks or Child $C$ class have an increased risk of bleeding, and should be treated with nonselective beta-blockers. Moreover, in patients with medium or large varices, nonselective beta-blockers or band ligation is recommended for prevention of the first bleeding. The choice of treatment should be based on local resources, expertise and contraindications [25, 26]. However, regarding the use of beta blockers, a recent retrospective study by Mandorfer et al. suggests that they are responsible for an increased hospitalization of hemodynamically compromised patients [27]. 
Acute hemorrhage from variceal rupture is well known to be an emergency in clinical practice. Bleeding occurs in approximately one-third of cirrhotic patients with varices. The precipitating cause remains still uncertain, with several factors implicated, such as bacterial infection, alcohol consumption, and increased intra-abdominal pressure. Mortality rates related to variceal bleeding are not significant in cirrhotic Child-Pugh Class A or B patients, while it is over $30 \%$ in Child-Pugh Class C [25]. There is a higher likelihood of mortality in those patients with active bleeding during endoscopy, in those with advanced cirrhosis (Child-Pugh Class $\mathrm{C}$ or a Model for End-Stage Liver Disease (MELD) score of $>20$ ), extra-hepatic organ failure, and high HVPG (>20 mmHg) [28].

Clinical management of hemorrhage requires airway maintenance and stabilization of hemodynamic conditions with IV vasoactive drugs (e.g., somatostatin), with further control of the variceal bleeding with available endoscopic techniques. According to the latest Baveno V guidelines, patients who do not respond to these measures are referred for TIPS as rescue treatment. Re-bleeding rates range from $30 \%$ to $40 \%$ at 6 weeks, with the mortality rate for rebleeding increased by up to $30 \%$. At present, a combination of beta-blockers and band ligation is the preferred therapy for prevention of re-bleeding [25].

\subsection{Ascites and spontaneous bacterial peritonitis}

The HS plays a major role in the pathogenesis of sodium retention and ascites in cirrhotic patients [4]. Ascites is the most common complication of cirrhosis, and about $60 \%$ of patients with compensated liver disease develop ascites during the clinical course of the disease [26]. Mortality is approximately $40 \%$ at 1 year, and 50\% at 2 years [26-31]. The most reliable predictors of poor prognosis include hyponatremia, low arterial pressure, increased serum creatinine, and low urine sodium [31]. Ascites usually occurs after development of PH, and is related to an incapacity to excrete an adequate amount of sodium into the urine, leading to a positive sodium balance.

The first evaluation of a patient with ascites should include anamnesis, physical examination, abdominal ultrasound, liver and renal function tests, serum and urine electrolytes, and analysis of the ascitic fluid. A diagnostic paracentesis is needed to exclude heart failure, pancreatic disease, malignancy, tuberculosis, or SBP. Ascites due to cirrhotic portal hypertension can be differentiated from ascites due to other causes by the serum-ascites albumin gradient: if the gradient is greater than or equal to $1.1 \mathrm{~g} / \mathrm{dl}$ (or $11 \mathrm{~g} / \mathrm{L}$ ), ascites is due to portal hypertension, with an accuracy of $97 \%$. Total ascitic fluid protein concentration should be measured to assess the risk of SBP because patients with a protein concentration of $<15 \mathrm{~g} / \mathrm{L}$ have a increased risk of SBP [31].

The current optimal management for mild ascites is a low salt and water diet. Dietary salt intake should be limited to $80-120 \mathrm{mmol}$ of sodium a day. Daily monitoring of body weight and urine output is essential. In patients with moderate ascites, the need for diuretics such as spironolactone (from $100 \mathrm{mg} /$ day to a maximum of $400 \mathrm{mg} /$ day) is the first step, followed by the introduction of furosemide (from $40 \mathrm{mg} /$ day to $160 \mathrm{mg} /$ day). In these cases, clinical responsiveness will be measured empirically by a reduction of body weight of less than $2 \mathrm{~kg} /$ week. In fact, the correct weight loss during diuretic therapy should vary from $0.5 \mathrm{~kg} /$ day to $1 \mathrm{~kg} /$ day in patients without or with edema, respectively. However, the goal of long-term treatment is to avoid renal impairment, hyponatremia, or severe hyperkalemia and their clinical manifestations such as hepatic encephalopathy or muscle cramps.

Large volume paracentesis and albumin infusion is the treatment of choice for patients with ascites resistant to diuretic treatment $[32,33]$. Paracentesis is an invasive, though safe procedure, with an extremely low risk of local complications such as hemorrhage or bowel perforation. Moreover, in patients with refractory ascites, the insertion of a transjugular intrahepatic portosystemic shunt (TIPS) should be considered. TIPS placement is not recommended in patients with severe liver failure and/or cardiopulmonary disease [31].

In the management of ascites it is important to recognize such ascites-related complications as SBP or HRS. Concerning SBP, bacterial infection in patients with cirrhosis and ascites is common [30,31,34]. The prevalence of SBP is $1.5-3.5 \%$ in outpatients, and about $10 \%$ in hospitalized patients [31,35]. The mortality is approximately $20 \%$ with early diagnosis and treatment. The clinical presentation is heterogeneous, ranging from asymptomatic patients to those with abdominal pain, nausea and vomiting, diarrhea, HE, renal failure, and hepatic insufficiency.

A diagnostic paracentesis with a neutrophil count of $>250 / \mathrm{mm} / \mathrm{c}$ should be obtained to exclude SBP [31]. Ascites fluid culture is negative in about $40 \%$ of cases, but in the remaining cases the most common pathogens include Gram-negative bacteria (Escherichia coli) and Gram-positive cocci (mainly streptococcus species and enterococci) $[31,36]$. This is important in determining antibiotic therapy, which usually employs cephalosporins, such as cephotaxime. A second paracentesis after 48 hours of the start of antibiotic therapy can help to guide therapy. Patients who recover from an episode of SBP have a high risk of developing recurrent SBP. The use of prophylactic antibiotics (norfloxacine or ciprofloxacine or co-trimoxazole) reduces the likelihood of recurrence [31]. However, patients who recover from SBP have a poor prognosis, with short-term survival, and should be considered for liver transplantation.

\subsection{Hepato-renal syndrome}

The renal circulation is indirectly affected by the consequences of the hyperdynamic state. The kidney, in response to the relative hypovolemia, retains sodium and water. Rather than a decrease in intravascular volume, the relative hypovolemia is the result of an increase of the vascular compartment caused by vasodilatation, leading to a reduction in central blood volume, and activation of vasoconstrictive and volume retaining neuro-humoral mechanisms that perpetuate the sodium- and water-retention $[4,37]$.

The HRS is a type of pre-renal failure resulting from an intense vasoconstriction of the renal circulation, and occurs in patients with advanced cirrhosis. Exclusion of other causes of renal failure is essential in arriving at a diagnosis of HRS. There are two clinical types of HRS. Type 1 HRS is an acute and rapidly progressive form of renal failure, with a rise in serum creatinine of $>2.5 \mathrm{mg} / \mathrm{dl}$, and an expected survival of only two weeks if the patient is not treated or transplanted $[31,38]$. It is common in severe alcoholic hepatitis, in patients with end-stage cirrhosis with SBP, though in some patients it can occur in the absence of any identifiable triggering event. In type 2 HRS, renal function is usually less compromised (serum creatinine $1.5-2.5 \mathrm{mg} / \mathrm{dl}$ ) than in HRS type 1 . The causes of HRS type 2 are usually refractory ascites and a moderate degree of functional renal failure. The management of HRS includes the monitoring of diuresis, fluid balance, and arterial pressure. Treatment options include discontinuing diuretic therapy, screening for sepsis, eventual antibiotic treatment and finally TIPS placement $[28,31]$.

The vasopressin-analogue terlipressin, together with the administration of albumin, is the first-line treatment for type 1 and 2 HRS, even if there are few data on the role of such drugs and/or vasoconstrictors in type 2 HRS [31,38-41]. Treatment response usually occurs within the first 7-10 days, and is associated with an increase in arterial pressure and urine volume $[31,42]$. Terlipressin is contraindicated in patients with ischemic cardiovascular diseases. Monitoring for development of cardiac arrhythmias, signs of digital or splanchnic ischemia, and fluid overload is mandatory. Other vasoconstrictors that have been used are alpha-adrenergic agonists, particularly noradrenalin, but, again few data are available [43].

TIPS represents a real treatment option, improving renal function in type 1 and 2 HRS, but its applicability is limited because of the severe liver failure. In fact, data from literature are few and survival may not be greatly improved in patients with poor liver function (advanced 
Child-Pugh score) [31]. However, regarding to this, some authors [44], reported the effects of TIPS in patients with type 2 HRS and ChildPugh score of 10-12, awaiting transplantation. All patients improved with respect to ascites and renal function thus, they conclude that TIPS is indicated in selected patients with HRS and/or in candidates for OLT.

HRS has a poor prognosis, even when vasoactive drug therapies are used. The impact of vasoactive drugs is poor, although their true effectiveness consists in prolonging short-term survival as a bridge to transplantation $[45,46]$.

\subsection{Hepatic encephalopathy}

HE is a serious neuropsychiatric complication of both acute and chronic liver failure, with the potential to affect health-related quality of life. The relation between the systemic vasodilatation occurring during chronic diseases and the cerebral circulation is probably the most difficult to delineate. Decreases, as well as increases, in cerebral blood flow have been reported, while an increase has been associated mainly with acute liver failure [47]. Studies on cerebral blood flow in cirrhosis have found that cerebral blood flow is normal in patients without HE, low or normal in those with subclinical encephalopathy, and markedly reduced in those with encephalopathy [48]. Dillon et al. measured the middle cerebral artery velocity with transcranial Doppler, an indirect estimate of cerebral blood flow, in 37 non-encephalopathic cirrhotic patients with varying degrees of liver dysfunction [49].

The middle cerebral artery velocity was normal in Child A patients, and significantly low in Child B and C patients. Guevara et al. found that in decompensated cirrhotic patients the cerebral vasoconstriction is likely related to the arterial hypotension and the hyperactivity of vasoconstrictor systems [50]. In a study by Lagy et al., cirrhotics were found to have an altered sympathetic regulation of the cerebral circulation, with inadequate microvessel resistance response, despite an adequate baroreceptor function [51]. However, though increasing systemic perfusion pressure is of benefit to the renal circulation, it could be detrimental to the brain. In fact, in acute liver failure, rises in cerebral blood flow lead to the development of brain edema [52].

Recently attention has been focused on the role of proinflammatory mechanisms that can act synergistically with ammonia toxicity, and result in the cerebral complications of acute and chronic liver failure [53].

$\mathrm{HE}$ is a complex and usually reversible syndrome, frequently observed in patients with advanced cirrhosis. The West-Haven criteria have been widely used to subjectively classify these patients according to the degree of depressed level of consciousness, personality changes, and neuropsychiatric abnormalities [54]. Because of the lack of typical features, clinical diagnosis requires a detailed neurological examination in order to exclude other causes of altered mental status. Clinical management includes discontinuation of sedative agents or, if necessary, use of short-acting benzodiazepines or propofol, as these can decrease intracranial pressure [55]. Symptomatic treatment of encephalopathy includes bowel decontamination with neomycin or rifaximin, and induction of diarrhea by administration of lactulose, thus reducing ammonia absorption, and treatment with branched-chain amino acids to improve peripheral ammonia metabolism, though large, randomized clinical trials have failed to show clinical improvement [56,57].

\subsection{Pulmonary complications}

\subsubsection{Hepatopulmonary syndrome}

The hyperdynamic circulation also affects the lungs and pulmonary circulation. Pulmonary involvement in cirrhosis includes two nosographic entities: HPS and POPH. The first occurs in $5-32 \%$ of cirrhotic patients. HPS is defined as the presence of liver disease and/or $\mathrm{PH}$ and intrapulmonary vascular dilatation, resulting in an abnormal age-corrected alveolar-arterial oxygen gradient (partial pressure of oxygen [PaO2] of $<80 \mathrm{mmHg}$, and an $\mathrm{AaPO} 2$ of $>15 \mathrm{mmHg}$, or $>20 \mathrm{mmHg}$ in patients $>64$ years of age) [58]. A taxonomy of the severity of the HPS based on alterations in oxygenation is essential because severity influences survival and is useful in determining the timing and the risks of orthotopic liver transplantation (OLT) [59,60]. The pulmonary gas exchange abnormalities of HPS are characterized by hyperventilation and arterial deoxygenation that can be mild ( $\mathrm{PaO} 2<80 \mathrm{mmHg}$ ), moderate ( $\mathrm{PaO} 2<70 \mathrm{mmHg}$ ), or severe ( $\mathrm{PaO} 2<60 \mathrm{mmHg}$ ) [58]. In some cases there are no specific signs and symptoms of the HPS on physical examination. However, the presence of spider nevi, digital clubbing, cyanosis and severe hypoxemia ( $\mathrm{PaO} 2<60 \mathrm{mmHg}$ ) strongly suggests a diagnosis of this condition. Orthodeoxia and platypnea seem to be further associated with ventilation-perfusion mismatch [61,59]. A chest radiograph is not adequate. Contrast-enhanced echocardiography is the most sensitive diagnostic tool, and commonly used in screening cirrhotic patients to detect intrapulmonary vascular dilatation [62]. No clearly effective medical therapy for HPS is available, though a number of experimental drugs have been studied. Currently, OLT is the only effective treatment for patients with these conditions, and complete resolution of gas exchange abnormalities is reported in more than $80 \%$ of cases [63]. Clinical practice indicates that independent of the MELD score, patients with cirrhosis diagnosed as suffering from HPS with a $\mathrm{PaO} 2<60 \mathrm{mmHg}$ are urgently listed for transplantation [64].

\subsubsection{Portopulmonary hypertension}

$\mathrm{POPH}$ is one of several pulmonary diseases that can affect patients with liver disease. The prevalence is $8-10 \%$ in patients with cirrhosis. When pulmonary hypertension occurs in the setting of $\mathrm{PH}, \mathrm{POPH}$ develops [65,66]. POPH is defined as an elevated mean pulmonary artery pressure (MPAP) at the time of right heart catheterization (MPAP > $25 \mathrm{mmHg},>30 \mathrm{mmHg}$ with exercise), with increased pulmonary vascular resistance ( $>240$ dines $\mathrm{s} / \mathrm{cm}^{3}$ ), and a pulmonary occlusion (wedge) pressure $\leq 15 \mathrm{~mm} \mathrm{Hg}$. POPH is classified as mild (MPAP $<35 \mathrm{~mm} \mathrm{Hg}$ ), moderate (MPAP $=35$ to $<45 \mathrm{~mm} \mathrm{Hg}$ ), or severe (MPAP $\geq 45 \mathrm{~mm} \mathrm{Hg}$ ) [64]. Mild POPH is common in cirrhosis, though usually negligible. Moderate and severe POPH are less common, and are associated with a higher mortality rate than that predicted by the MELD score. Pellicelli et al., found that patients with POPH had significantly higher levels of endothelin 1 and IL- 6, suggesting a role of these mediators as targets in the management of POPH [67]. Physical manifestations can be absent or non-specific, and dyspnea can be present. Echocardiography is required as screening for patients undergoing OLT evaluations, and right heart catheterization is required to confirm the diagnosis. The management of POPH includes different classes of drugs, such as prostacyclin analogues, endothelin receptor antagonists, and PDE5 inhibitors. Recent data show that sildenafil has the advantage of being an oral compound with pulmonary vaso-selective action, but no hepatotoxicity $[68,69]$. OLT is a potentially curative therapeutic option for POPH patients. The mortality rate after OLT is $50 \%$ if the MPAP is $>35 \mathrm{~mm} \mathrm{Hg}$, and 100\% if the MPAP is $>50 \mathrm{~mm} \mathrm{Hg}$ [70]. In fact, efficient pharmacologic control of $\mathrm{POPH}$ before transplantation is associated with post-transplant survival that is similar to that of patients transplanted for other indications $[70,71]$.

\subsubsection{Hepatic hydrothorax}

$\mathrm{HH}$ is a complication of $\mathrm{PH}$, characterized by a transudative pleural effusion in the absence of cardiac or pulmonary disease. The estimated prevalence is $5-10 \%$ in cirrhotic patients, predominantly right in $70 \%$ of cirrhotics, left in $18 \%$ and bilateral in $12 \%$. Data indicates that only $6.5 \%$ of these patients require thoracentesis [72]. The most common mechanism leading to the passage of ascitic fluid from the peritoneal to the pleural cavity is the presence of diaphragmatic defects and a portal hypertensive state [73].

Clinical manifestations include dyspnea, cough, chest discomfort, hypoxia and, in the most severe cases, respiratory distress. Ascites is 
detected in $80 \%$ of these patients. Chest $\mathrm{X}$ ray is required to show pleural effusion. Thoracentesis is indicated to identify other causes of effusion, fluid infection, and to ameliorate dyspnea. Management includes diuretics and, occasionally, percutaneus drainage.

As for ascites, a complication of $\mathrm{HH}$ is spontaneous bacterial pleuritis. A PMN count of $>500$ cells $/ \mathrm{mm} 3$ is diagnostic for infection in pleural effusion, though spontaneous bacterial pleuritis with PMN between 250 and 500 cells $/ \mathrm{mm} 3$ is documented by positive pleural fluid culture [74]. In these cases, the mortality rate is $20 \%$. Treatment includes antibiotic and albumin infusion. In cases of refractory HH, TIPS placement can be recommended. Thoracoscopy with pleurodesis is a potential treatment alternative for patients with refractory $\mathrm{HH}$ who are not eligible for, or have failed, TIPS placement [75,76].

\subsection{Cirrhotic cardiomyopathy}

CC is defined as chronic cardiac dysfunction in patients with chronic liver disease, and is characterized by impaired contractile function in response to stress, altered diastolic function, and electrophysiological abnormalities, in the absence of known cardiovascular disease. This condition is independent of the etiology of cirrhosis and has been linked to an impairment of myocardial structure and function [77]. However, several studies have reported a wide spectrum of cardiovascular changes in cirrhotic patients, ranging from the sub-clinical stage of compensated liver disease to the typical hyperkinetic state of HS in decompensated disease $[78,79]$. The prevalence of CC is unknown, because diagnosis is difficult, and cardiac function at rest is usually normal.

Patients with CC remain asymptomatic for a long time because the arterial vasodilation due to reduced vascular peripheral resistances leads to a reduction in the after-load, which covers the severe cardiac dysfunction. Heart failure becomes evident when during certain procedures, such as large volume paracentesis, TIPS placement, and liver transplantation, there is an acute increase in the cardiac pre-load following the rise of effective blood volume. A correct diagnosis becomes evident during the ascitic phase of the cirrhosis, when the cardiac output is increased.

Echocardiography assessments of systolic and diastolic function, ECG, or magnetic resonance cardiac imaging are the best available methods for screening cirrhotic patients at risk of developing CC. Clinical suspicion of CC can be confirmed by pharmacologic (dobutamine stress echocardiography) or physical stress test (physical exercise) $[80,81]$. The impaired systolic response to stress is the trigger of development of pulmonary edema and congestive heart failure following procedures that suddenly increase blood flow to the heart. At-rest cardiac pressures are normal in cirrhosis, so that chamber size modifications are modest, as demonstrated by magnetic resonance, likely due to diastolic dysfunction. A marker of initial cardiac damage has been indentified and proven in analysis of NT pro- brain natriuretic peptide (BNP), a pro hormone of the BNP, commonly used to screen patients with cardiac dyspnea. NT pro BNP is a sensitive marker of myocardial injury, and has been found at high levels in both compensated and decompensated cirrhosis [82]. In fact, it has been recently correlated with the severity of cirrhosis (Child-Pugh class, HVPG and serum albumin), degree of cardiac dysfunction (plasma volume, heart rate and QT interval) and myocardiac hypertrophy. Diastolic dysfunction is characterized by an abnormal pattern of transmitral flow and increased atrial input to the late ventricular filling. A number of studies have reported electrophysiological abnormalities as common findings of cardiac dysfunction in liver cirrhosis. Electrocardiographic abnormalities are an early manifestation of cardiac changes in patients with liver disease: a prolongation of the QT interval, which is the hallmark of the ECG alterations could be related to severity of liver disease $[83,84]$. Worsening of cardiac function after OLT, however, is brief and resolves within about 6 months, when the hyperdynamic circulation disappears. A normalization of cardiac function and amelioration of electrophysiological abnormalities are usually observed in these patients $[78,85,86]$. In conclusion, clinical understanding of CC in endstage liver disease is the best way to avoid life-threatening consequences in patients undergoing special procedures (TIPS or OLT).

\section{Conclusions}

The HS is a complex of hemodynamic alterations involving patients with cirrhosis and $\mathrm{PH}$. The pathophysiological mechanisms that characterize the HS are complex and only partially known.

Multi-organ involvement is crucial, and is characterized by a set of more or less explored complications of cirrhosis. Clinical manifestations of PH such as ascites, esophageal varices, and HRS have been described in numerous studies, while the HPS and CC remain among the least explored and understood manifestations of HS. Pathophysiological and hemodynamic studies on both experimental and human models are needed to better understand the mechanisms involved in these conditions, and to identify new therapeutic strategies.

\section{Learning points}

- In clinical practice, portal hypertension has been defined as an increase in the hepatic venous pressure gradient (HPVG), and PPG values of at least $12 \mathrm{mmHg}$ are usually associated with the presence of esophageal varices.

- Arteriolar vasodilatation, low systemic vascular resistance, expanded blood volume, and raised sympathetic nervous activity contribute to increased cardiac output, and to configuring the hemodynamic changes typical of hyperdynamic circulation.

- Esophageal varices are present in 30-40\% of compensated cirrhotic patients, and in up to $60 \%$ of decompensated cirrhotics. Mortality rates related to variceal bleeding are $30 \%$ in Child-Pugh Class C patients. Upper endoscopy is mandatory in all patients with cirrhosis at diagnosis.

- The HPS occurs in $5-32 \%$ of cirrhotic patients. Typical pattern is gas exchange abnormalities ( $\mathrm{PaO} 2<80 \mathrm{mmHg}$; AaPO2 $>15 \mathrm{mmHg}$, or $>20 \mathrm{mmHg}$ in patients $>64$ years of age), and intrapulmonary vascular dilation. Patients with a $\mathrm{PaO} 2<60 \mathrm{mmHg}$ are urgently listed for liver transplantation.

- Cirrhotic cardiomyopathy is defined as chronic cardiac dysfunction characterized by impaired contractile function in response to stress, altered diastolic function, and electrophysiological abnormalities, in the absence of known cardiovascular disease. Cardiac function usually improves significantly within 6 months after liver transplantation.

\section{Conflict of interest}

None.

\section{References}

[1] Gines P, Arroyo V, Rodes J. Pathophysiology, complications, and treatment of ascites Clin Liver Dis 1997;1:129-55.

[2] Iwakiri Y, Groszmann RJ. The hyperdynamic circulation of chronic liver diseases: from the patient to the molecule. Hepatology 2006;43:S121-31.

[3] Kowalski HJ, Abelmann WH. The cardiac output at rest in Laennec's cirrhosis. J Clin Invest 1953;32:1025-33.

[4] Bosch J, Abraldes JG, Berzigotti A, García-Pagan JC. The clinical use of HVPC measurements in chronic liver disease. Nat Rev Gastroenterol Hepatol 2009;6(10): 573-82. http://dx.doi.org/10.1038/nrgastro.2009.149.

[5] García-Pagán JC, Gracia-Sancho J, Bosch J. Functional aspects on the pathophysiology of portal hypertension in cirrhosis. J Hepatol 2012;57(2):458-61. http://dx.doi.org/ 10.1016/j.jhep.2012.03.007.

[6] Groszmann RJ, Garcia-Tsao G, Bosch J, Grace ND, Burroughs AK, Planas R, et al. Portal Hypertension Collaborative Group. $\beta$-blockers to prevent gastroesophageal varices in patients with cirrhosis. N Engl J Med 2005;353(21):2254-61. http://dx.doi.org/ 10.1056/NEJMoa044456.

[7] Fernández M, Semela D, Bruix J, Colle I, Pinzani M, Bosch J. Angiogenesis in liver disease. J Hepatol 2009;50(3):604-20. http://dx.doi.org/10.1016/j.jhep.2008.12.011. 
[8] Hamilton G, Phing RC, Hutton RA, Dandona P, Hobbs KE. The relationship between prostacyclin activity and pressure in the portal vein. Hepatology 1982;2: 236-42.

[9] Bruix J, Bosch J, Kravetz D, Mastai R, Rodes J. Effects of prostaglandin inhibition on systemic and hepatic hemodynamics in patients with cirrhosis of the liver. Gastroenterology 1985;88:430-5.

[10] Iwakiri Y. The molecules: mechanisms of arterial vasodilation observed in the splanchinc and systemic circulation in portal hypertension. J Clin Gastroenterol 2007;41:S288-94.

[11] Geerts AM, De Vriese AS, Vanheule E, Van Vlierberghe H, Mortier S, Cheung KJ, et al. Increased angiogenesis and permeability in the mesenteric microvasculature of rats with cirrhosis and portal hypertension: an in vivo study. Liver Int 2006;26: 889-98.

[12] Moller S, Bendtsen F, Henriksen JH. Effect of volume expansion on systemic hemodynamics and central and arterial blood volume in cirrhosis. Gastroenterology 1995;109:1917-25.

[13] Abraldes JG, Iwakiri Y, Loureiro-Silva M, Haq O, Sessa WC, Groszmann RJ. Mild increases in portal pressure upregulate vascular endothelial growth factor and endothelial nitric oxide synthase in the intestinal microcirculatory bed, leading to a hyperdynamic state. Am J Physiol Gastrointest Liver Physiol 2006;290:G980-7.

[14] Wiest R, Jurzik L, Herold T, Straub RH, Scholmerich J. Role of NPY for vasoregulation in the splanchnic circulation during portal hypertension. Peptides 2007:28:396-404.

[15] Song D, Liu H, Sharkey KA, Lee SS. Hyperdynamic circulation in portal-hypertensive rats is dependent on central c-fos gene expression. Hepatology 2002;35:159-66.

[16] Coll M, Genesca J, Raurell I, Rodriguez-Vilarrupla A, Mejias M, Otero T, et al. Down-regulation of genes related to the adrenergic system may contribute to splanchnic vasodilation in rat portal hypertension. J Hepatol 2008;49:43-51.

[17] Brinch K, Moller S, Bendtsen F, Becker U, Henriksen JH. Plasma volume expansion by albumin in cirrhosis. Relation to blood volume distribution, arterial compliance and severity of disease. J Hepatol 2003;39:24-31.

[18] Schrier RW. Water and sodium retention in edematous disorders: role of vasopressin and aldosterone. Am J Med 2006;119:S47-53.

[19] Kontos HA, Shapiro W, Mauck HP, Patterson Jr JL. General and regional circulatory alterations in cirrhosis of the liver. Am J Med 1964;37:526-35.

[20] Maroto A, Gines P, Arroyo V, Gines A, Salo J, Claria J, et al. Brachial and femoral artery blood flow in cirrhosis: relationship to kidney dysfunction. Hepatology 1993;17: 788-93.

[21] Luca A, Garcia-Pagan JC, Feu F, Lopez-Talavera JC, Fernandez M, Bru C, et al. Noninvasive measurement of femoral blood flow and portal pressure response to propranolol in patients with cirrhosis. Hepatology 1995;21:83-8.

[22] Carrella M, Hunter JO, Fazio S, Del Piano C, Bartoli GC. Capillary blood flow to the skin of forearm in cirrhosis. Angiology 1992;43:969-74.

[23] Berzigotti A, Seijo S, Reverter E, Bosch J. Assessing portal hypertension in liver diseases. Expert Rev Gastroenterol Hepatol Feb 2013;7(2):141-55. http://dx.doi. org/10.1586/egh.12.83 [Review].

[24] Garcia-Tsao G, Bosch J, Groszmann RJ. Portal hypertension and variceal bleedingunresolved issues. Summary of an American Association for the study of liver diseases and European Association for the study of the liver single-topic conference. Hepatology 2008;47:1764-72.

[25] De Franchis R, Baveno V Faculty. Revising consensus in portal hypertension: report of the Baveno $\mathrm{V}$ consensus workshop on methodology of diagnosis and therapy in portal hypertension. J Hepatol 2010;53(4):762-8

[26] Madonia S, D'Amico G, Traina M, Gatto G, Virdone R, Salamone N, et al. Prognostic indicators of successful endoscopic sclerotherapy for prevention of rebleeding from oesophageal varices in cirrhosis: a long-term cohort study. Dig Liver Dis Dec 2000;32(9):782-91 [PMID11215559].

[27] Mandorfer M, Bota S, Schwabl P, Bucsics T, Pfisterer N, Kruzik M, et al. Nonselective $\beta$ blockers increase risk for hepatorenal syndrome and death in patients with cirrhosis and spontaneous bacterial peritonitis. Gastroenterology 2014;146(7):1680-90. http://dx.doi.org/10.1053/j.gastro.2014.03.005.

[28] Ripoll C, Groszmann R, Garcia-Tsao G, Grace N, Burroughs A, Planas R, et al. Hepatic venous gradient predicts clinical decompensation in patients with compensated cirrhosis. Gastroenterology 2007;133:481-8.

[29] Guevara M, Cárdenas A, Uriz J, Ginès P. Prognosis in patients with cirrhosis and ascites. In: Ginès P, Arroyo V, Rodés J, Schrier RW, editors. Ascites and renal dysfunction in liver disease: pathogenesis, diagnosis and treatment. Malden: Blackwell; 2005. p. 260-70.

[30] Rimola A, García-Tsao G, Navasa M, Piddock LJ, Planas R, Bernard B, et al. Diagnosis, treatment and prophylaxis of spontaneous bacterial peritonitis: a consensus document. International Ascites Club. J Hepatol 2000;32:142-53.

[31] European Association for the Study of the Liver. EASL clinical practice guidelines on the management of ascites, spontaneous bacterial peritonitis, in hepatorenal syndrome in cirrhosis. J Hepatol Sep 2010;53(3):397-417. http://dx.doi.org/10 1016/j.jhep.2010.05.004 [Epub 2010 Jun 1].

[32] Ginés P, Arroyo V, Quintero E, Planas R, Bory F, Cabrera J, et al. Comparison of paracentesis and diuretics in the treatment of cirrhotics with tense ascites. Results of a randomized study. Gastroenterology 1987;92:234-41.

[33] Ginès A, Fernandez-Esparrach $G$, Monescillo A, Vila $C$, Domènech $E$, Abecasis R, et al. Randomized controlled trial comparing albumin, dextran-70 and polygelin in cirrhotic patients with ascites treated by paracentesis. Gastroenterology 1996;111: 1002-10.

[34] Caly WR, Strauss E. A prospective study of bacterial infections in patients with cirrhosis. J Hepatol 1993;18:353-8.

[35] Wong F, Bernardi M, Balk R, Christman B, Moreau R, Garcia-Tsao G, et al. Sepsis in cirrhosis: report on the 7th meeting of the International Ascites Club. Gut 2005; 54:718-25.
[36] Nousbaum JB, Cadranel JF, Nahon P, Nguyen Khac E, Moreau R, Thévenot T, et al. Diagnostic accuracy of the Multistix 8 SG_reagent strip in diagnosis of spontaneous bacterial peritonitis. Hepatology 2007;45:1275-81.

[37] Arroyo V, Terra C, Gines P. Advances in the pathogenesis and treatment of type-1 and type-2 hepatorenal syndrome. J Hepatol 2007;46:935-46.

[38] Salerno F, Gerbes A, Gines P, Wong F, Arroyo V. Diagnosis, prevention and treatment of hepatorenal syndrome in cirrhosis. Gut 2007;56:1310-8.

[39] Bagshaw SM, George C, Dinu I, Bellomo R. A multi-centre evaluation of the RIFLE criteria for early acute kidney injury in critically ill patients. Nephrol Dial Transplant 2008;23:1203-10.

[40] Arroyo V, Fernandez J, Gines P. Pathogenesis and treatment of hepatorenal syndrome. Semin Liver Dis 2008;28:81-95.

[41] Gines P, Schrier RW. Renal failure in cirrhosis. N Engl J Med 2009;361:1279-90.

[42] Sanyal AJ, Boyer T, Garcia-Tsao G, Regenstein F, Rossaro L, Appenrodt B, et al. A randomized, prospective, double-blind, placebo-controlled trial of terlipressin for type 1 hepatorenal syndrome. Gastroenterology 2008;134:1360-8.

[43] Martin-Llahi M, Pepin MN, Guevara M, Diaz F, Torre A, Monescillo A, et al. Terlipressin and albumin vs albumin in patients with cirrhosis and hepatorenal syndrome: a randomized study. Gastroenterology 2008;134:1352-9.

[44] Testino G, Ferro C, Sumberaz A, Messa P, Morelli N, Guadagni B, et al. Type-2 hepatorenal syndrome and refractory ascites: role of transjugular intrahepatic portosystemic stent-shunt in eighteen patients with advanced cirrhosis awaiting orthotopic liver transplantation. Hepatogastroenterology Nov-Dec 2003;50(54): 1753-5.

[45] Piano S, Morando F, Fasolato S, Cavallin M, Boscato N, Boccagni P, et al. Continuous recurrence of type 1 hepatorenal syndrome and long-term treatment with terlipressin and albumin: a new exception to MELD score in the allocation system to liver transplantation? J Hepatol 2011;55:491-6.

[46] Licata A. Maida M, Bonaccorso A. Macaluso FS, Cappello M. Craxì A, et al. Clinical course and prognostic factors of hepatorenal syndrome: A retrospective single-center cohort study. World J Hepatol Dec 27 2013;5(12):685-91. http://dx. doi.org/10.4254/wjh.v5.i12.685.

[47] Blei AT. Monitoring cerebral blood flow: a useful clinical tool in acute liver failure? Liver Transpl 2005;11:1320-2.

[48] Larsen FS. Cerebral circulation in liver failure: Ohm's law in force. Semin Liver Dis 1996;16:281-92

[49] Dillon JF, Plevris JN, Wong FC, Chan KH, Lo NT, Miller JD, et al. Middle cerebral artery blood flow velocity in patients with cirrhosis. Eur J Gastroenterol Hepatol 1995;7: 1087-91.

[50] Guevara M, Bru C, Gines P, Fernandez-Esparrach G, Sort P, Bataller R, et al. Increased cerebrovascular resistance in cirrhotic patients with ascites. Hepatology 1998;28: 39-44.

[51] Lagi A, Laffi G, Cencetti S, Barletta G, Foschi M, Vizzutti F, et al. Impaired sympathetic regulation of cerebral blood flow in patients with cirrhosis of the liver. Clin Sci (Lond) 2002;103:43-51.

[52] Vaquero J, Chung C, Blei AT. Cerebral blood flow in acute liver failure: a finding in search of a mechanism. Metab Brain Dis 2004;19:177-94.

[53] Butterworth Roger F. Hepatic encephalopathy: a central neuroinflammatory disorder? Hepatology 2011;53(4).

[54] Ferenci P, Lockwood A, Mullen K, Tarter R, Weissenborn K, Blei AT, et al. Hepatic encephalopathy - definition, nomenclature, diagnosis, and quantification: final report of the working party at the 11th World Congresses of Gastroenterology, Vienna, 1998. Hepatology 2002;35(3).

[55] Wijdicks EF, Nyberg SL. Propofol to control intracranial pressure in fulminant hepatic failure. Transplant Proc 2002;34:1220-2.

[56] Larson AM. Diagnosis and management of acute liver failure. Curr Opin Gastroenterol 2010;26:214-21.

[57] Nguyen NT, Vierling JM. Acute liver failure. Curr Opin Organ Transplant 2011;16: 289-96.

[58] Rodriguez-Roisin R, Krowka MJ. Hepatopulmonary syndrome - a liver-induced lung vascular disorder. N Engl J Med 2008;358:2378-87.

[59] Swanson K, Wiesner R, Krowka M. Natural history of hepatopulmonary syndrome: impact of liver transplantation. Hepatology 2005;41:1122-9.

[60] Arguedas MR, Abrams GA, Krowka MJ, Fallon MB. Prospective evaluation of outcomes and predictors of mortality in patients with hepatopulmonary syndrome undergoing liver transplantation. Hepatology 2003;37:192-7.

[61] Rodriguez-Roisin R, Krowka MJ, Herve P, Fallon MB. Pulmonary-hepatic vascular disorders [PHD]. Eur Respir J 2004;24:861-80.

[62] Abrams GA, Jaffe CC, Hoffer PB, Binder HJ, Fallon MB. Diagnostic utility of contrast echocardiography and lung perfusion scan in patients with hepatopulmonary syndrome. Gastroenterology 1995; 109:1283-8.

[63] Goldberg DS, Krok K, Batra S, Trotter JF, Kawut SM, Fallon MB. Impact of the hepatopulmonary syndrome MELD exception policy on outcomes of patients after liver transplantation: an analysis of the UNOS database. Gastroenterology Jan 8 2014. http://dx.doi.org/10.1053/j.gastro.2014.01.005 [pii: S0016-5085(14)00015-8].

[64] Fallon MB, Mulligan DC, Gisch RG, Krowka MJ. Model for end-stage liver disease [MELD] exception for hepatopulmonary syndrome. Liver Transpl 2006;12:s105-7 [Suppl.].

[65] Jyothula S, Safdar Z. Update on pulmonary hypertension complicating chronic obstructive pulmonary disease. Int J Chron Obstruct Pulmon Dis 2009;4:351-63.

[66] Simonneau G, Robbins IM, Beghetti M, Channick RN, Delcroix M, Denton CP, et al. Updated clinical classification of pulmonary hypertension. J Am Coll Cardiol 2009; 54:S43-54 [Suppl.]

[67] Pellicelli AM, Barbaro G, Puoti C, Guarascio P, Lusi EA, Bellis L, et al. Plasma cytokines and portopulmonary hypertension in patients with cirrhosis waiting for orthotopic liver transplantation. Angiology 2010;61:802-6. 
[68] Kawut SM, Taichman DB, Ahya VN, Kaplan S, Archer-Chicko CL, Kimmel SE, et al. Hemodynamics and survival of patients with portopulmonary hypertension. Liver Transpl 2005;11:1107-11.

[69] Safdar Z, Bartolome S, Sussman N. Portopulmonary hypertension: an update. Liver Transpl 2012;18(8):881-91.

[70] Sussman N, Kaza V, Barshes N, Stribling R, Goss J, O’ Mahony C, et al. Successful liver transplantation following medical management of portopulmonaryhypertension: a single-center series. Am J Transplant 2006;6:2177-82. http://dx.doi.org/10.1111/j. 1600-6143.2006.01432.x [PMID: 16796721].

[71] Ashfaq M, Chinnakotla S, Rogers L, Ausloos K, Saadeh S, Klintmalm GB, et al. The impact of treatment of portopulmonary hypertension on survival following liver transplantation. Am J Transplant 2007;7:1258-64. http://dx.doi.org/10.1111/j. 1600-6143.2006.01701.x [PMID: 17286619].

[72] Malagari K, Nikita A, Alexopoulou E, Brountzos E, Papathanasiou M, Mitromaras J, et al. Cirrhosis-related intrathoracic disease. imaging features in 1038 patients. Hepatogastroenterology 2005;52:558-62.

[73] Machicao VI, Balakrishnan M, Fallon MB. Pulmonary complications in chronic liver disease. Hepatology Apr 2014;59(4):1627-37. http://dx.doi.org/10.1002/hep. 26745 [Epub 2014 Feb 25].

[74] Xiol X, Castellvi JM, Guardiola J, Sese E, Castellote J, Perello A, et al. Spontaneous bacterial empyema in cirrhosis patients: a prospective study. Hepatology 1996;23: 719-23.

[75] Gordon FD, Anastopoulos HT, Crenshaw W, Gilchrist B, McEniff N, Falchuk KR, et al. The successful treatment of symptomatic, refractory hepatic hydrothorax with transjugular intrahepatic portosystemic shunt. Hepatology 1997;25:1366-9.

[76] Milanez de Campos JR, Filho LO, de Campos Werebe E, Sette Jr H, Fernandez A, Filomeno LT, et al. Thoracoscopy and talc poudrage in the management of hepatic hydrothorax. Chest 2000;118:13-7.
[77] Zardi EM, Abbate A, Zardi DM, Dobrina A, Margiotta D, Van Tassell BW, et al. Cirrhotic cardiomyopathy. J Am Coll Cardiol Aug 10 2010;56(7):539-49.

[78] Møller S, Henriksen JH. Cardiovascular complications of cirrhosis. Postgrad Med J 2009;85:44-54

[79] Abelmann WH, Kowalski Mc, Neely WF. The Hemodynamic Response to Exercise in patients with Laennec's Cirrhosis. J Clin Invest 1955;34(5):690-5.

[80] Kim Y, Baik SK, Suk KT, Kim JW, Kim HS, Kwon SO, et al. Dobutamine stress echocardiography: a new screening method for evaluating cirrhotic cardiomyopathy in liver cirrhosis. Hepatology 2008;48:1064F.

[81] Donovan CL, Marcovitz PA, Punch JD, Bach DS, Brown KA, Lucey MR, et al Two-dimensional and dobutamine stress echocardiography in the preoperative assessment of patients with end-stage liver disease prior to orthotopic liver transplantation. Transplantation 1996;61:1180-8.

[82] Licata A, Corrao S, Petta S, Genco C, Cardillo M, Calvaruso V, et al. NT Pro BNP plasma level and atrial volume Are linked to the severity of liver cirrhosis. PLoS One Aug 5 2013;8(8):e68364. http://dx.doi.org/10.1371/journal.pone.0068364.

[83] Bal JS, Thuluvath PJ. Prolongation of QTc interval: relationship with etiology and severity of liver disease, mortality and liver transplantation. Liver Int 2003;23: 243-8.

[84] Wong F. Cirrhotic cardiomyopathy. Hepatol Int Mar 2009;3(1):294-304.

[85] Torregrosa M, Aguadé S, Dos L, Segura R, Gónzalez A, Evangelista A, et al. Cardiac alterations in cirrhosis: reversibility after liver transplantation. J Hepatol 2005;42: 68-74.

[86] Milani A, Zaccaria R, Bombardieri G, Gasbarrini A, Pola P. Cirrhotic cardiomyopathy. Dig Liver Dis Jun 2007;39(6):507-15. 